\title{
'n Vergelyking van verskillende metodes om swangerskapstadiums te bepaal
}

\author{
Y Janse van Rensburg, MSocSc (Verpl.), Skool vir Verpleegkunde, UV \\ D Botha, MSocSc (Verpl.), Skool vir Verpleegkunde, UV \\ R Nel, BSocSc, Departement Biostatistiek, UV \\ A Fichardt, University of the Free State, School of Nursing
}

\section{Abstract}

A group of 208 antenatal women at a primary health care clinic in Bloemfontein was selected for the study. Fundal height was determined by measuring the height of the fundus as well as using the uterine fundus height in relation to weeks method. The above-mentioned methods were compared with a sonar date to determine whether a specific method is more accurate in a specific stage of pregnancy. It seems as if measuring of the height of the fundus is more accurate in the second trimester. In the third trimester of pregnancy a tendency exists for both the uterine fundus height in relation to weeks method and measuring of the height of the fundus to be accurate until the 36th week of pregnancy. After the 36 th week of pregnancy the uterine fundus height in relation to weeks method seems to be more accurate.

\section{Opsomming}

'n Groep van 208 voorgeboorte-vroue van 'n primêregesondheidsorg-kliniek in Bloemfontein is vir die doel van die studie geselekteer. Fundale hoogte is volgens beide die simfise-fundus-hoogte-meting-metode as die abdominale-weke-indeling-metode bepaal. Genoemde twee metodes is met sonardatums vergelyk om te bepaal of " $n$ spesifieke metode tydens ' $n$ spesifieke stadium van swangerskap meer akkuraat is. Na raming skyn die simfisefundus-hoogte-meting-metode meer akkuraat tydens die tweede trimester van swangerskap te wees. In die derde trimester van swangerskap neig beide die abdominale-wekeindeling-metode en die simfise-fundus-hoogte-metingmetode akkuraat tot op 36-weke-swangerskapsduur te wees. $\mathrm{Na}$ 36-weke-swangerskpasduur skyn die abdominale-wekeindeling-metode meer akkuraat te wees.

\section{Inleiding en probleemstelling}

Die akkurate berekening van swangerskapsduur is een van die belangrikste faktore in die versekering van effektiewe voorgeboortesorg. Hoë-risiko-pasiënte, insluitend pasiënte met intra-uteriene-groeivertraging, polihidramnios, oligohidramnios en meervoudige swangerskappe, kan vroegtydig deur middel van die akkurate berekening van swangerskapsduur geïdentifiseer en behandel word.

Swangerskapsduur kan deur middel van verskillende metodes bereken word. Die algemeenste metodes is die volgende:

- Volgens die dag van konsepsie

- Volgens Naegele se reël

- Met behulp van sonar

- Volgens fundale hoogte

Alhoewel swangerskapsduur akkuraat vanaf die dag van konsepsie en/of volgens Naegele se reël bereken kan word, is dit nie altyd moontlik om hierdie twee metodes te gebruik nie. Min swanger pasiënte kan die presiese dag van konsepsie en/ of die eerste dag van die laaste normale menstruele siklus onthou, wat vir die berekening van swangerskapsduur volgens hierdie metodes noodsaaklik is (Brummer, Cronje, Grobler \& Visser, 1993:83; Chamberlain \& Pearce, 1992:31).
Naas die berekening van swangerskapsduur deur hierdie twee metodes, word ' $n$ sonar, geneem voor 24-wekeswangerskapsduur, as die akkuraatste metode erken (Chamberlain \& Pearce, 1992:1; Chudleigh \& Pearce, 1986:49).

Die berekening van swangerskapsduur volgens die fundale hoogte is ' $n$ tegniek wat geen tegnologie benodig nie. Dit kan bereken word deur of die abdominale-weke-indeling-metode, waar die hoogte van die fundus ten opsigte van sekere abdominale, anatomiese landmerke aan ' $n$ spesifieke swangerskapsduur gekoppel word, óf deur die simfise-fundushoogte-meting-metode, waar die afstand tussen die borand van die simfisiepubis en die rand van die fundus met 'n nie-elastiese maatband in sentimeter gemeet word.(Nel, 1995:9).

Brummer et al. (1993:94) beskryf die abdominale-weke-indelingmetode tot die hoogte van die umbilikus (22-wekeswangerskapsduur) as betreklik akkuraat. In teenstelling hiermee beweer $\mathrm{Nel}$ (1995:8) dat hierdie metode na 26-wekeswangerskapsduur akkuraat is.

Met betrekking tot die simfise-fundus-hoogte-meting-metode bevind Jimenez, Tyson en Reisch (1983:438), asook OIds, London en Ladewig (1996:332) dat die metingsmetode veral gedurende 20-31-weke-swangerskapsduur akkuraat is. Nel (1995:8) beskryf die metode as akkuraat tot 26-weke- 
swangerskapsduur, terwyl Brummer et al. (1993:94) die simfisefundus-hoogte-meting veral in die laaste trimester (28-42 weke swangerskapsduur) van swangerskap meer akkuraat bevind het.

Daar is dus nie eenstemmigheid oor die stadium van swangerskap waartydens die abdominale-weke-indelingmetode of die simfise-fundus-hoogte-meting-metode die akkuraatste is nie.

Engstrom en Sittler (1993:5) is egter van mening dat die simfise-fundus-hoogte-meting-metode, ongeag swangerskapsduur, akkurater as die abdominale-wekeindeling-metode is. Die skrywers grond hul stelling daarop dat die umbilikushoogte, wat onder andere as merker in die abdominale-weke-indelingmetode gebruik word, by swanger pasiënte varieer. Net so is daar ' $n$ groot variasie in die afstand tussen die umbilikus en die xifistemum. Swangerskapsduurberekening deur middel van die abdominale-weke-indeling-metode kan dus, as gevolg van hierdie variasies, tot onakkurate gegewens lei.

Die skrywers van hierdie artikel het waargeneem dat die abdominale-weke-indeling-metode sowel as die simfise-fundushoogte-meting-metode gedurende die voorgeboorte- en intrapartum-tydperk vir die berekening van swangerskapsduur gebruik word.

Aangesien primêregesondheidsorgdienste verskillende metodes en tegnieke gebruik en nie almal sonar tot hul beskikking het nie, het die vraag onstaan of die abdominale-weke-indelingmetode en die simfise-fundus-hoogte-meting-metode ewe akkuraat op enige gegewe tydstip in swangerskap en/of intrapartum is.

\section{Doel van die studie}

Die doel van die studie was om te bepaal watter metingsmetode, hetsy die abdominale-weke-indeling-metode of die simfise-fundus-hoogte-meting-metode, in vergelyking met sonar, die akkuraatste tydens ' $n$ spesifieke stadium van swangerskap is.

\section{Metodes}

' $n$ Beskrywende ontwerp is vir die doel van die studie gebruik. Die populasie was alle swanger vroue wat die voorgeboortekliniek van die Mangaung-UVgemeenskapsvennootskapprogram voorgeboorte-kliniek gedurende Mei 1998 besoek het. Gerieflikheidsteekproefneming is gebruik om vroue wat aan die insluitingskriteria voldoen het, in die steekproef in te sluit. Insluitingskriteria was as volg: ingeligte, skriftelike toestemming tot deelname, swangerskapsduur van meer as 12 weke gewees het, ' $n$ eenmalige, roetinesonar vir die berekening van swangerskapsduur moes voor 24 weke en 'n massa van minder as 95 kilogram. Tweehonderd-en-agt vroue_is by die studie ingesluit.

\section{Dataversameling}

Fisiologiese meting deur middel van direkte observasie is as metingstrategie gebruik. Om inter- en intrawaarnemingsvariasie te beperk, het die een navorser persoonlik slegs van die abdominale-weke-indeling-metode gebruik gemaak. Hiervolgens is die hoogte van die fundus ten opsigte van sekere abdominale anatomiese landmerke aan ' $n$ spesifieke swangerskapsduur gekoppel. So, byvoorbeeld, is die fundus op die hoogte van die simfise gelyk aan 12-wekeswangerskapsduur, en op die hoogte van die umbilikus gelyk aan 22-weke-swangerskapsduur (Nel, 1995:9). 'n Veldwerker, 'n professionele verpleegkundige, het weer slegs van die simfise-fundus-hoogte-meting-metode gebruik gemaak. Beide metingsmetodes is ten opsigte van elke pasiënt gebruik. ' $n$ Dubbelblinde studie is uitgevoer, wat beteken dat nog die navorser, nog die veldwerker enige voorkennis van die pasiënt se swangerskapsduur gehad het nie. Geen vrae aan die pasiënt in verband met swangerskapsduur is toegelaat nie. Hiema is waardes gekaart en met swangerskapsduur, soos deur middel van sonar bereken, vergelyk.

\section{Data-analise}

Beskrywende statistiek, naamlik frekwensies en persentasies, is vir kategoriese data bereken, en gemiddeldes en standaardafwykings vir numeriese data. Die verskillende metodes is vergelyk deur middel van $95 \%$-grense van ooreenstemming (Altman, 1991:16). Die Departement Biostatistiek, UV, het die ontledings uitgevoer. Die SPSS program is gebruik.

' $n$ Verskil van twee of meer weke is as klinies beduidend beskou. Dit beteken dat die resultate van die metodes met meer as twee weke van sonardatums moes verskil alvorens dit vir praktiese (kliniese) doeleindes as betekenisvol beskou sou word. Die rede is die verwagte geboortedatum volgens sonar met ' $n$ reikwydte van een tot twee weke bereken word.

Data is in die tweede en derde trimester onderskeidelik verdeel, vergelyk en ontleed. In die derde trimester van swangerskap is data ook in voor (26-35-weke-swangerskapsduur) en na (3640-weke-swangerskapsduur) afdaling van die voorliggende deel van die fetus verdeel, vergelyk en ontleed.

\section{Resultate}

Die gemiddelde ouderdom van die vroue was 27 jaar (reikwydte 15 tot 39 jaar). Vyf-en-dertig persent was primigravidas en $34,1 \%$ gravida twee. Die gemiddelde swangerskapsduur was 32 weke volgens die sonar, 30 weke volgens die simfise-fundus-hoogtemeting-metode (SFH) en 32 weke volgens die abdominale-wekeindeling-metode.

In die tweede trimester van swangerskap (12-25-wekeswangerskapsduur) is 27 vroue ondersoek. Die gemiddelde verskil tussen die resultate van die sonar en die simfise-fundus-hoogte-meting-metode was slegs 0,1 week met $95 \%$ grense 
die gemiddelde verskil tussen die resultate van die sonar en die abdominale-weke-indeling-metode $-3,2$ met $95 \%$ grense van ooreenstemming $-8,88$ tot 2,48 weke. Die gemiddelde verskil tussen die resultate van die simfise-fundus-hoogte-metingmetode en die abdominale-weke-indeling-metode was $-3,3$ met $95 \%$ grense van ooreenstemming $-8,32$ tot 1,72 weke. In 18,5 $\%$ van die gevalle het die berekende swangerskapsduur volgens die simfise-fundus-hoogte-meting-metode met meer as twee weke van die sonar verskil. Die berekening volgens die abdominale-weke-indeling-metode het in $51,9 \%$ van die gevalle met meer as twee weke van die sonar verskil.

In die derde trimester van swangerskap (26-40-wekeswangerskapsduur) is 173 vroue ondersoek. Die gemiddelde verskil tussen die berekende swangerskapsduur volgens die sonar en die simfise-fundus-hoogte-meting-metode was 1,6 met $95 \%$ grense van ooreenstemming $-3,34$ tot 6,54 (Tabel 2). Daarteenoor was die gemiddelde verskil tussen die berekening van die sonar verskil. Die berekening volgens die abdominaleweke-indeling-metode het in $23,7 \%$ van die gevalle met meer as twee weke van die sonar verskil.

Tydens 26 tot 35-weke-swangerskapsduur is 109 vroue ondersoek. Die gemiddelde verskil tussen die berekende swangerskapsduur volgens die sonar en die simfise-fundushoogte-meting-metode was 0,9 met grense van ooreenstemming $-3,74$ tot 5,54 weke (tabel 3). Die gemiddelde verskil tussen die berekening volgens die sonar en die abdominale-weke-indelingmetode was 0,2 met $95 \%$ grense van ooreenstemming $-4,86$ tot 5,26 , die gemiddelde verskil tussen die berekening van die simfise-fundus-hoogte-meting-metode en die abdominaleweke-indeling-metode was $-0,8$ met $95 \%$ grense van ooreenstemming $-5,44$ tot 3,84 . In $32,1 \%$ van die gevalle het die berekening volgens die simfise-fundus-hoogte-metingmetode met meer as twee weke van die sonar verskil. Die

\section{Tabel 1: Verskillende tussen tegnieke: Tweede trimester van swangerskap ( $<26$ weke) $(\mathrm{N}=27)$}

\begin{tabular}{|l|c|c|c|}
\hline & Gemiddelde & Standaardafwyking & $\begin{array}{l}95 \% \text { grense van } \\
\text { ooreenstemming }\end{array}$ \\
\hline Sonar - SFH & 0,1 & 1,88 & $(-3,66 ; 4,76)$ \\
\hline Sonar-abdominale - weke & $-3,2$ & 2,84 & $(-8,88 ; 2,48)$ \\
\hline SFH - abdominale - weke & $-3,3$ & 2,51 & $(-8,32,1,72)$ \\
\hline
\end{tabular}

\section{Tabel 2: Verskllle tussen tegnieke: Derde trimester van swangerskap ( $>26$ weke) $(N=173)$}

\begin{tabular}{|l|c|c|c|}
\hline & Gemiddelde & Standaardafwyking & $\begin{array}{c}95 \% \text { grense van } \\
\text { ooreenstemming }\end{array}$ \\
\hline Sonar-SFH & 1,6 & 2,47 & $(-3,34 ; 6,54)$ \\
\hline Sonar-abdominale - weke & 0,1 & 2,33 & $(-4,56 ; 4,76)$ \\
\hline SFH - abdominale - weke & $-1,5$ & 2,68 & $(-6,86 ; 3,86)$ \\
\hline
\end{tabular}

volgens diesonar en die abdominale-weke-indeling-metode 0,1 met $95 \%$ grense van ooreenstemming $-4,56$ tot 4,76 weke. Die gemiddelde verskil tussen die berekende swangerskapsduur volgens die simfise-fundus-hoogte-meting-metode en die abdominale-weke- indeling-metode was $-1,5$ met $95 \%$ grense van ooreenstemming $-6,86$ tot 3,86 . Die simfise-fundus-hoogtemeting-metode neig dus om die swangerskapsduur as korter te bereken as die sonar en abdominale-weke-indeling-metode, maar die abdominale-weke-indeling-metode en simfise-fundushoogte-meting-metode is albei onakkuraat. In $41,0 \%$ van die gevalle het die berekende swangerskapsduur volgens die simfise-fundus-hoogte-meting-metode met meer as twee weke berekening volgens die abdominale-weke-indeling-metode het in $25,7 \%$ van die gevalle metmeer as twee weke van die sonar verskil.

Tydens 36-40-weke-swangerskapsduur is 64 vroue ondersoek. Die gemiddelde verskil tussen die berekende swangerskapsduur volgens die sonar en die simfise-fundushoogte-meting-metode was 2,8 met $95 \%$ grense van ooreenstemming $-1,76$ tot 7,36 . Daarteenoor was die gemiddelde verskil tussen die berekening volgens die sonar en die abdominale-weke-indeling-metode $-0,1$ met $95 \%$ grense van ooreenstemming -4 tot 3,8 . Die gemiddelde verskil tussen die berekening volgens die simfise-fundus-hoogte-meting-metode 


\section{TABEL 3: Verskille tussen tegnieke: 26-35 weke swangerskap ( $N=109)$}

\begin{tabular}{|l|c|c|c|}
\hline & Gemiddelde & Standaardafwyking & $\begin{array}{l}\text { 95\% grense van } \\
\text { ooreenstemming }\end{array}$ \\
\hline Sonar - SFH & 0,9 & 2,32 & $(-3,74 ; 5,54)$ \\
\hline Sonar-abdominale - weke & 0,2 & 2,53 & $(-4,86 ; 5,26)$ \\
\hline SFH - abdominale - weke & $-0,8$ & 2,32 & $(-5,44 ; 3,84)$ \\
\hline
\end{tabular}

\section{TABEL 4: Verskille tussen tegnieke: $36-40$ weke swangerskap $(N=64)$}

\begin{tabular}{|l|c|c|c|}
\hline & Gemiddelde & Standaardafwyking & $\begin{array}{c}95 \% \text { grense van } \\
\text { ooreenstemming }\end{array}$ \\
\hline Sonar - SFH & 2,8 & 2,28 & $(-1,76 ; 7,36)$ \\
\hline Sonar-abdominale - weke & $-0,1$ & 1,95 & $(-4 ; 3,8)$ \\
\hline SFH - abdominale - weke & $-2,8$ & 2,75 & $(-8,3 ; 2,7)$ \\
\hline
\end{tabular}

die simfise-fundus-hoogte-meting-metode neig dus om nog laer te wees in vergelyking met die sonar in die tydperk 36-40 weke as in die tydperk 26-35 weke. Soos die grense van ooreenstemming aandui, is albei tegnieke onakkuraat. In 56,2 $\%$ van die gevalle het die berekenings volgens die simfisefundus-hoogte-meting-metode met meer as twee weke van die sonar verskil. Die berekening volgens die abdominale-wekeindeling-metode het in $20,3 \%$ van die gevalle metmeer as twee weke van die sonar verskil.

\section{Gevolgtrekking}

Die resultate kan soos volg saamgevat word: in die tweede trimester van swangerskap neig die berekening volgens die simfise-fundus-hoogte-meting-metode om nader aan die sonarwaarde te wees, terwyl dit in die derde trimester laer as die sonar neig. In die derde trimester van swangerskap neig die berekening volgens die abdominale-weke-indeling-metode weer om nader aan die sonarwaarde te wees, terwyl dit in die tweede trimester hoër as die sonar neig. Indien die derde trimester in twee verdeel word en data voor (26-35 weke) en na (36-40 weke) afdaling van die voorliggende deel van die fetus vergelyk word, blyk dit dat beide metodes tussen 26-35 weke swangerskapsduur baie akkuraat is. Na 36-weke-swangerskapsduur blyk egter slegs die abdominale-weke-indeling-metode baie akkuraat te wees. $\mathrm{Na}$ aanleiding van bogenoemde resultate, word die volgende aanbevelings gemaak:

- Die simfise-fundus-hoogte-meting-metode moet verkieslik gedurende die tweede trimester van swangerskap gebruik word.
- $\quad$ As die derde trimester in twee verdeel word, kan die simfise-fundus-hoogte-meting-metode sowel as die abdominale-weke-indeling-metode tot op 36 weke swangerskapsduur gebruik word om swangerskapsduur te bereken.

- $\quad$ Nadat afdaling van die voorliggende deel van die fe -tus op ongeveer 36-weke-swangerskapsduur begin het, moet die abdominale-weke-indeling-metode verkieslik gebruik word.

\section{Verwysings}

ALTMAN DG 1991: Practical statistics for medical research. London: Chapman \& Hall.

BRUMMER WE; CRONJE HS; GROBLER CJF \& VISSER AA 1993: Verloskunde. Pretoria: Academica.

CHAMBERLAIN G \& PEARCE JM 1992: Lecture Notes on Obsteterics. $6^{\text {th }}$ ed. Oxford: The Alden Press.

CHUDLEIGH P \& PEARCE JM 1986: Obstetric ultrasound: how, why and when. Aylesbury: Churchill Livingstone.

ENGSTROM JL \& STILLER CP 1993: Fundal height measurement: Part 1 -techniques for measuring fundal height. Journal of Nurse-Midwifery, 38(1):5-16.

JIMENEZ JM; TYSON JE \& REISCH JS 1983: Clnical measures of gestational age in normal pregnancies. Obstetric $G y$ - 
NEL JT 1995: Kernverloskunde en -ginekologie met eksamenwenke vir M.B.Ch.B. Johannesburg: Heinemann.

OLDS SB; LONDON ML \& LADEWIG PW 1996: Maternalnewborn nursing: a family-centered approach. United States of America: The Benjamin/Cummings Publishing Company 